\title{
ORGANOSOLV PULPING OF WHEAT STRAW
}

\section{Trembus Iryna ${ }^{1}$ \\ Halysh Vita ${ }^{2}$}

DOI: http://dx.doi.org/10.30525/978-9934-571-26-8_19

Abstract. The aim of the study was the development of scientifically grounded technological modes for the production of pulp from wheat straw by more environmentally friendly organosolv methods of delignification and its application in the composition of cardboard and paper products. The influence of the temperature mode, cooking time and the consumption of chemicals on the quality indices of organosolv straw pulp was studied in details. The influence of the catalytic action of anthraquinone on the quality indices of straw pulp obtained by ammonia sulfite-alcohol and twostage alkaline-alcohol methods of cooking was studied. It was established that the use of anthraquinone with the consumption of $0.1 \%$ of oven dry material contributes to an increase in yield by $2-6 \%$ in the case of twostage alkaline-alcohol delignification, a decrease in the content of lignin by $0.4-1.0$ and $0.3-1.9 \%$, respectively, and an increase in physical and mechanical properties on average by $25-30 \%$, compared with similar pulping without catalyst. The regression equations of the processes of obtaining straw pulp using the method of a full factorial design were obtained. Optimization methods using a generalized Harrington's desirability function were applied to obtain optimal parameters for organosolv delignification of wheat straw. The indices of the selectivity of lignin dissolution from wheat straw during pulping and the kinetic characteristics of the investigated methods of delignification were calculated. It was established that the highest selectivity correspond to ammonia-sulfite-alcohol and alkaline-sulphite-alcohol methods of delignification of wheat straw. It was proved that organosolv delignification is described by kinetic equations of the second order and is characterized by lower values of activation energy in comparison with wood delignification. The possibility of bleaching of organosolv straw pulp

\footnotetext{
${ }^{1} \mathrm{PhD}$, Associate Professor of the Department of Ecology and Plant Polymer Technologies, National Technical University of Ukraine "Igor Sikorsky Kyiv Polytechnic Institute", Ukraine ${ }^{2} \mathrm{PhD}$, Senior Lecturer of the Department of Ecology and Plant Polymer Technologies,

National Technical University of Ukraine "Igor Sikorsky Kyiv Polytechnic Institute", Ukraine

(C) Trembus Iryna, Halysh Vita
} 
without use of molecular chlorine was investigated. It was found out that for organosolv pulp bleaching the scheme C-P-A can be recommended, with the consumption of hydrogen peroxide of 3-5\%, which allows one to obtain pulp with brightness up to $80 \%$. The papermaking properties of the obtained pulps were investigated and its practical suitability for the production of cardboard and paper products was shown. It was found out that ammonia sulfite-alcohol and alkaline-sulfite-alcohol straw unbleached pulps can be used in a composition with recycling paper for the production of packaging paper, and bleached alkali-sulphite-alcohol unbleached pulp from straw in a composition with bleached sulfate softwood pulp for the production of writing paper.

\section{Introduction}

Nowadays, the products of the pulp and paper industry (PPI) are extremely important for the development of culture, education and scientific, also for technological progress. In the production of paper and cardboard, such fibrous products as cellulose pulp, waste paper and wood pulp can be used. In world practice, the dominant methods of obtaining cellulose pulp are sulfate and sulfite methods, which are the main source of environmental pollution due to the pollution of air with mercaptans, hydrogen sulfide, dioxins, furans and water with lignin derivatives. The amount of organic wastes from these types of cooking of plant material is 2-3 million tons per year [1, p. 37].

In the world PPI, in order to obtain pulp bisulfite and neutral sulfite methods of delignification are also can be used [2, p. 2127]. Pulp from plant material with an yield of 50-53\% was obtained by acid-bisulfite cooking on the magnesium base; such pulp was characterized by high content of lignin due to the presence of unpulped particles and with gray color, therefore it did not find a wide industrial application in the unbleached form.

For obtaining pulp from non-woods, neutral sulfite method of delignification is the most widely used [2, p. 2127]. The yield of unbleached neutral-sulfite pulp from straw is $53-55 \%$ and $47-48 \%$ is for bleached. Tthe industrial application of this method of delignification is connected with a strong problem of the regeneration of monosulfite from the spent liquor.

In order to reduce the environmental problem, scientists develop alternative methods of cooking: organosolv, hydrotropic, biotechnological, etc. [3, p. 67]. Among such methods, organosolv pulping of plant material is 
the most developed and implemented in production. The application of organosolv cooking [3, p. 67] allows one to reduce the use of fresh water (5-10 $\mathrm{m}^{3}$ per 1 ton of cellulose instead of $50-100 \mathrm{~m}^{3}$, which is typical for traditional technologies) and investments by $20-30 \%$, as compared to the production of sulfate hardwood pulp. The technology of organosolv cooking involves the complex processing of raw materials, the utilization of waste and by-products with the receiving of valuable materials and substances (plastics, furfural, etc.) [3, p. 67].

In the world PPI, wood is the main raw material for the production of pulp. For countries that have short stocks of wood, the search for alternative sources of fibrous products is an urgent problem. Different representatives of non-wood plant material (NWPM), in particular, stems of cereal crops, can be regarded as source of pulp.

An attractive aspect in the production of pulp from wheat straw stems is its availability and lower cost in comparison with wood. Fibers of agricultural plants can be processing into fibrous product more economically advantageously, mainly in small volumes and using simple technologies, which require much less investments than wood processing.

According to the chemical composition, wheat straw has a lower content of lignin and a higher content of low molecular weight fractions of polysaccharides such as hemicelluloses (pentosans and hexoses) than those in wood. The hemicelluloses are characterized with hydrophilicity and high ability to swell, they can plasticized fibers, promote hydration, facilitate their fibrillation, thereby contributing to the formation of a dance paper sheet. Therefore, the development of new environmentally safe technologies for the production of pulp from wheat straw by organosolv methods of delignification and their use in the composition of cardboard and paper products is an important scientific and technical issue.

In this study, different methods of analysis were used to determine the quality indices of organosolv pulp from wheat straw, as well as cardboard and paper based on obtained straw pulp.

\section{Organosolv methods of delignification}

Organic solvents, which are used to delignify plant material, can belong to one or more classes of organic compounds (monoatomic and polyhydric alcohols, phenols and carboxylic acids, ethers and esters, ketones and amines). Classification of organosolv methods of cooking is shown in Fig. 1. 
To choose an organic solvent and to develop organosolv technology for the production of pulp from plant raw materials, it is necessary to consider the technological process and the characteristics of the quality of the obtained fibrous products, also the possibility of multi-tonnage solvent production, the possibility of using a simple regeneration of the solvent, its consumption must be taking into account too.

The solvent should not increase the corrosion activity of the cooking solution and excessively increase the fire and explosion hazard of the production. From an environmental point of view, the solvent must be suitable for biological degradation and must be non-toxic. Taking into account these factors, the range of solvents for pulping was narrowed to ethanol, methanol, acetone, acetic acid and monoethyl ether of ethylene glycol.

For organosolv delignification of plant material, binary hydrogen-organic solutions are widely used, that increase the efficiency of lignin removal and the process of regeneration of the solvent can be applied.

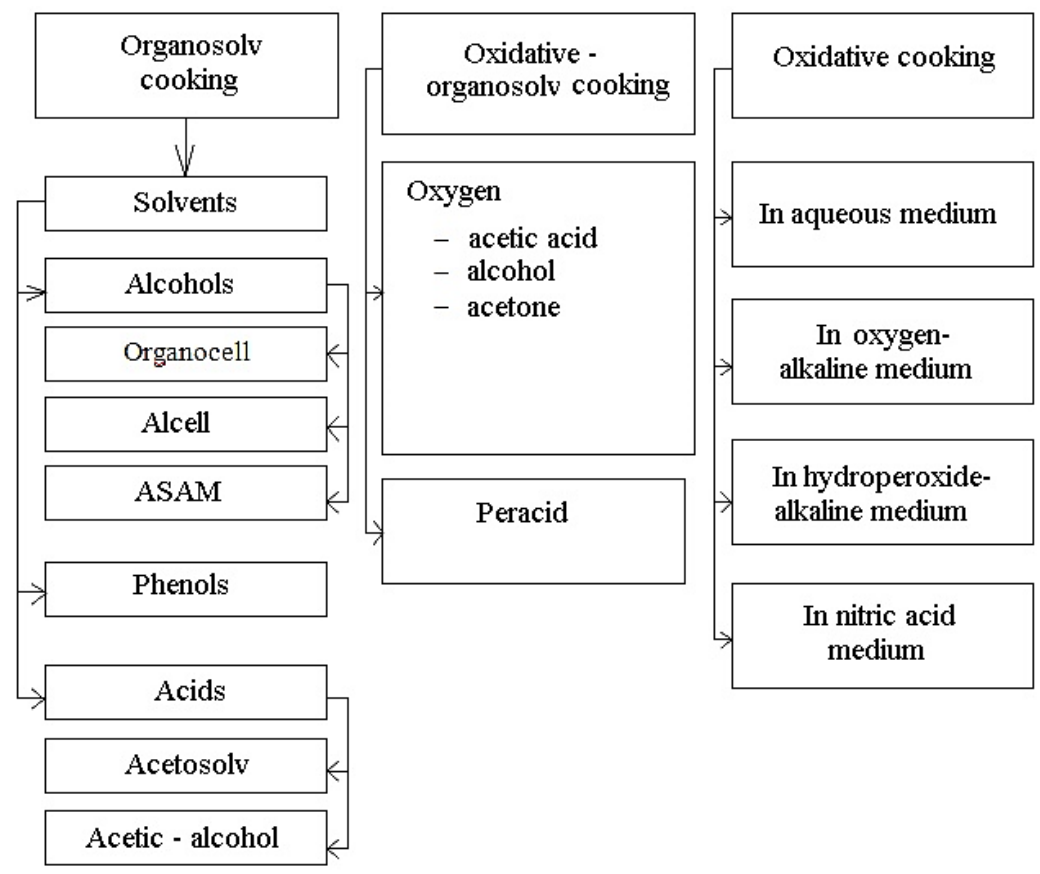

Fig. 1. Classification of organosolv methods of cooking 
For theoretical substantiation of the investigated methods of obtaining straw fibrous products, it is necessary to consider the chemistry of the basic processes of organosolv cooking.

\section{Chemistry of delignification in organosolv pulping}

The process of organosolv delignification is characterized not only by the reactions of hydrolytic degradation of lignin, but also by the influence of the components of cooking solution on carbohydrates, primarily on hemicelluloses, which determines the yield and quality of the fibrous products. The degree of such influence depends on the composition of the organosolv cooking solution and the conditions of the process.

Organic solvents used in organosolv methods of delignification, differ in the chemistry of interaction with the components of plant material and technological parameters of the process of cooking. Thus, they can be used as chemical reagent, as well as the medium, in which the process of delignification takes place. As a chemical reagent, organic solvents interact with reactive groups of lignin, which leads to the destruction of lignin or the blockage of reactive hydroxyl groups of benzyl alcohol (to prevent lignin condensation reactions). As a medium, organic solvents can positively influence the physical and chemical processes that occur during cooking: impregnation, swelling, solubility of lignin degradation products.

The absence of strong nucleophiles that are used in traditional cooking solutions, as well as the ability of the solvent to affect the acid-alkali balance and the rate of chemical reactions, add some features to the characterization of organosolv solutions [4, p. 186]. The nature of the process of organosolv delignification depends on the $\mathrm{pH}$ of the cooking solution. In the acidic medium $(\mathrm{pH}=2-4)$, the destruction of the mesh structure of lignin occurs as a result of the acid splitting of the $\alpha$-etheric bonds of lignin with the formation of intermediate carbocations (Fig. 2) [5, p. 813].

As it known, in the hardwood species the fraction of non-cyclic structures of the $\alpha$-aryl ether, that responsible for the destruction of lignin, is almost 2 times higher than that in softwood species. Therefore, delignification of hardwood and non-wood materials in the acidic medium occurs easier unlike softwood species. In this case, the organic solvent, like a weak nucleophile, blocks the active centers of lignin and prevents the process of its condensation

During organosolv cooking in the acid medium, the $\beta$-ether bonds of lignin (especially $\beta-\mathrm{O}-4$ bond) are also degraded, unlike to chemical trans- 


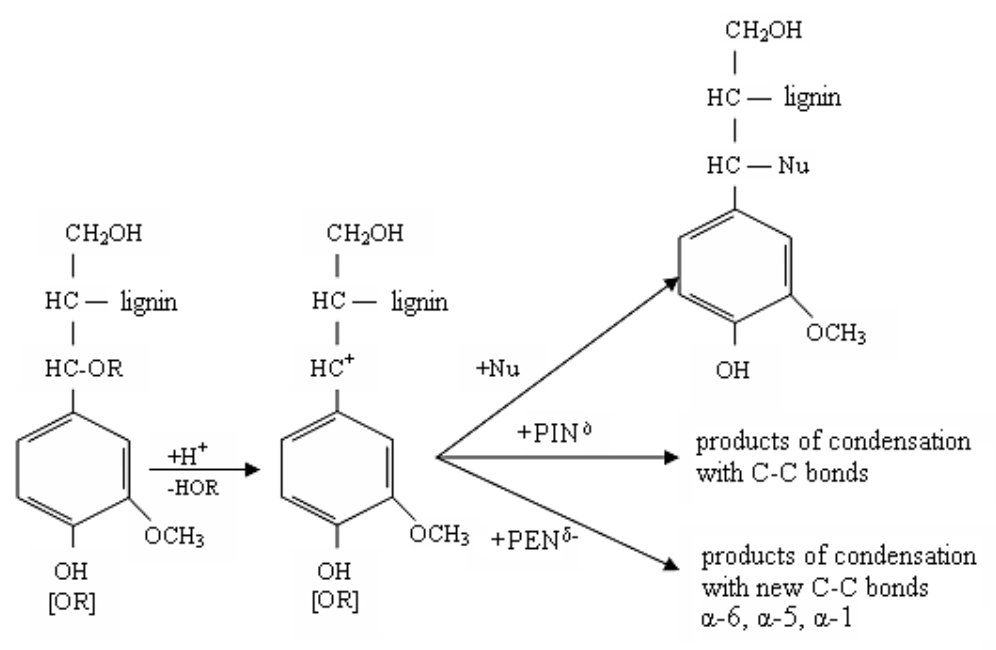

Fig. 2. Splitting of $\alpha$-etheric bonds of lignin during organosolv cooking of plant material in acid medium:

$\mathrm{Nu}$ - external nucleophile ( $\mathrm{HOH}, \mathrm{C}_{2} \mathrm{H}_{5} \mathrm{OH}, \mathrm{CH}_{3} \mathrm{OH}$, etc.); $\mathrm{PIN}^{\delta-}-$ internal nucleophile (phenilpropane unit of lignin); $\mathrm{PEN}^{\delta-}$ - external nucleophile of phenolic type (phenol, cresols, etc).

formations that occur during traditional acidic sulfite pulping of plant material (Fig. 3).

At the same time, the degradation of the $\beta-\mathrm{O}-4$ bond leads to the splitting of the $\gamma$-methyl group in the form of formaldehyde and the formation of ketones. Reduction of dielectric permittivity of the cooking solution with the use of organic solvent and raising the temperature of cooking, promotes hemolytic degradation of $\beta$-etheric bonds of lignin and the freely radical reactions that lead to the process of condensation of lignin take place.

In an alkali medium, the destruction of lignin takes place through the splitting of $\alpha$-etheric bonds through to the intermediate structure - quinone-methyl (Fig. 4, 5), which is blocked by an organic solvent and prevents the process of condensation of lignin.

Alkylation of hydroxyl $\mathrm{OH}$ group in $\alpha$-position with an alcohol promotes the fragmentation of lignin due to improving its dissolution in an 


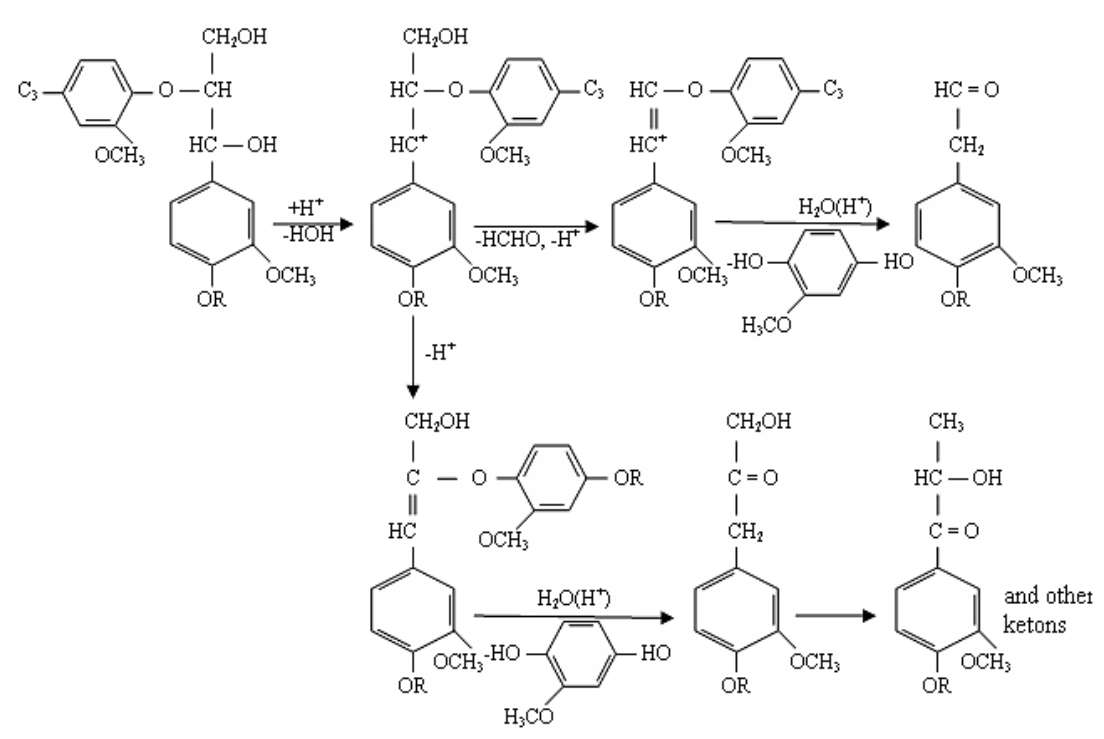

Fig. 3. Splitting of $\beta$-etheric bonds of lignin during organosolv cooking of plant material in acid medium

organic solvent. In addition, in the alkali medium, condensation processes are less developed than at $\mathrm{pH}<7$. All this leads to a greater selectivity of the lignin dissolution process (obtaining a larger yield of cellulose at 3 to $5 \%$ with the same content of lignin) compared with organosolv cooking in acid medium.

Physical and mechanical properties of organosolv pups also depend on the $\mathrm{pH}$ of organic solutions. Thus, fibrous products obtained in an acid medium are generally characterized by lower parameters than those obtained in an alkali medium. This is especially true in the case of tear index, the value of which is depended on the content of hemicelluloses in pulp, on the structure of the resulting fibrous product, on the surface properties of the fibers.

It also should be noted that the process of organosolv delignification in an alkali medium is characterized by a greater selectivity of the lignin removal from plant raw materials in comparison with organosolv cooking methods that take place in an acid medium. 


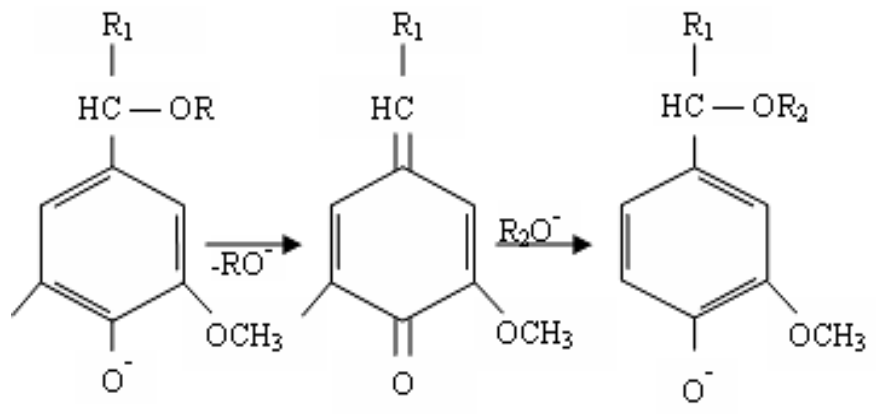

Fig. 4. Splitting of $\alpha$-ether bonds of lignin during organosolv cooking of plant material in alkali medium: $\mathrm{R}=\mathrm{H}, \mathrm{Ar}, \mathrm{Alk} ; \mathrm{R}_{1}=\mathrm{HC}<\underset{\mathrm{OAr}}{\mathrm{CH}_{2} \mathrm{OH}} ; \mathrm{R}_{2}=\mathrm{Me}$, Et, etc.

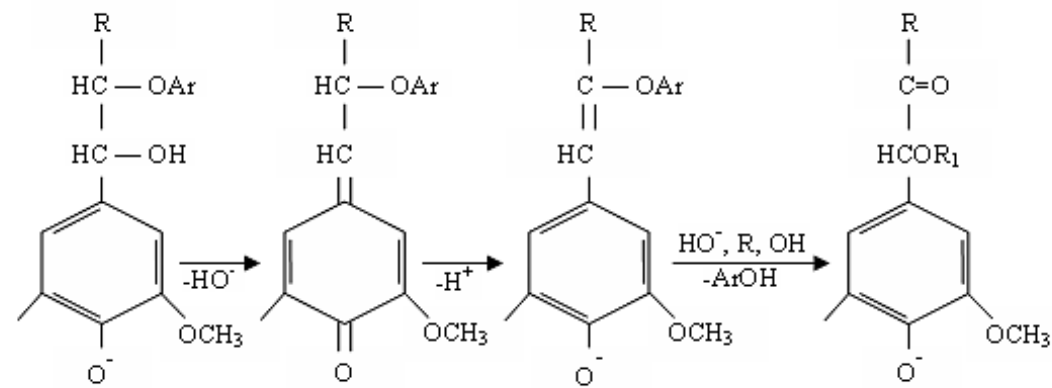

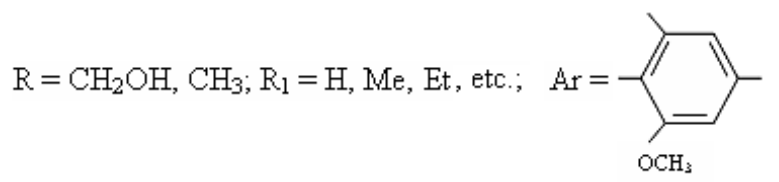

Fig. 5. Splitting of $\beta-O-4$ ether bonds of lignin during organosolv cooking of plant material in alkali medium

\section{Obtaining of straw pulp}

Organosolv methods of delignification of wheat straw that were investigated are: acetic (As), etheric (ES), two-stage alkaline-alcoholic (2AS), ammonia sulfite-alcoholic (ACC) and alkaline sulfite-alcohol (ASAE). 
Anthraquinone was used as a catalyst for the intensification of some of these methods. The comparative characteristic of organosolv pulping of wheat straw is given in Table. 1.

During cooking wheat straw with acetic acid it was possible to obtain pulp with the degree of delignification from 42.7 to 95.4 Kappa number and low mechanical strength. In addition, the increased corrosion of such cooking solution leads to additional investments, and indicates the inappropriate of industrial application of this method.

The equal parts of acetic acid, ethyl acetate and water as delignify solution can be used. The choice of acetic ester is done due to the fact that, in its presence, the spent liquor can be easily divided into two layers - aqueous with hemicelluloses sugars and organic with lignin compounds, that simplifies the regeneration of chemicals.

The high content of residual lignin, relatively low mechanical properties of the obtained straw pulp (Table 1), gives grounds for arguing about low industrial use of this method of delignification for the production of fibrous products suitable for the production of paper and cardboard.

Cooking of wheat straw in hydrogen-alcohol solutions allows one to produce pulp of high yield and with low content of residual lignin in comparison with sulfate and sulfite methods of delignification of plant material. Delignification of wheat straw in water-alcohol solutions, for example, according to the 2 AS method, as well as hydrogen-alcohol solutions of ammonia and sulfur dioxide (ACC method), allows to receive straw pulp with an yield of 58.8 to $86.1 \%$ and the content of lignin from 1.8 to $11 \%$ (Table 1).

The use of anthraquinone as the catalyst reduces the yield of 2AS organosolv straw pulp due to reducing the content of lignin in it and increases the mechanical properties of obtained fibrous product. The proposed delignification of plant material can be considered as an alternative way of obtaining pulp suitable for the production of paper and cardboard products.

The use of anthraquinone as the catalyst during ACC cooking of wheat straw helps increase the yield of cellulose, its mechanical characteristics and reduces lignin content in it by $0,3-1,9 \%$ compared to cooking without catalyst. Pulp, obtained in this way, can be bleached without the use of molecular chlorine and its mechanical parameters are comparable to the similar characteristics of sulfate wood pulp [6, p. 345]. 
Trembus Iryna, Halysh Vita

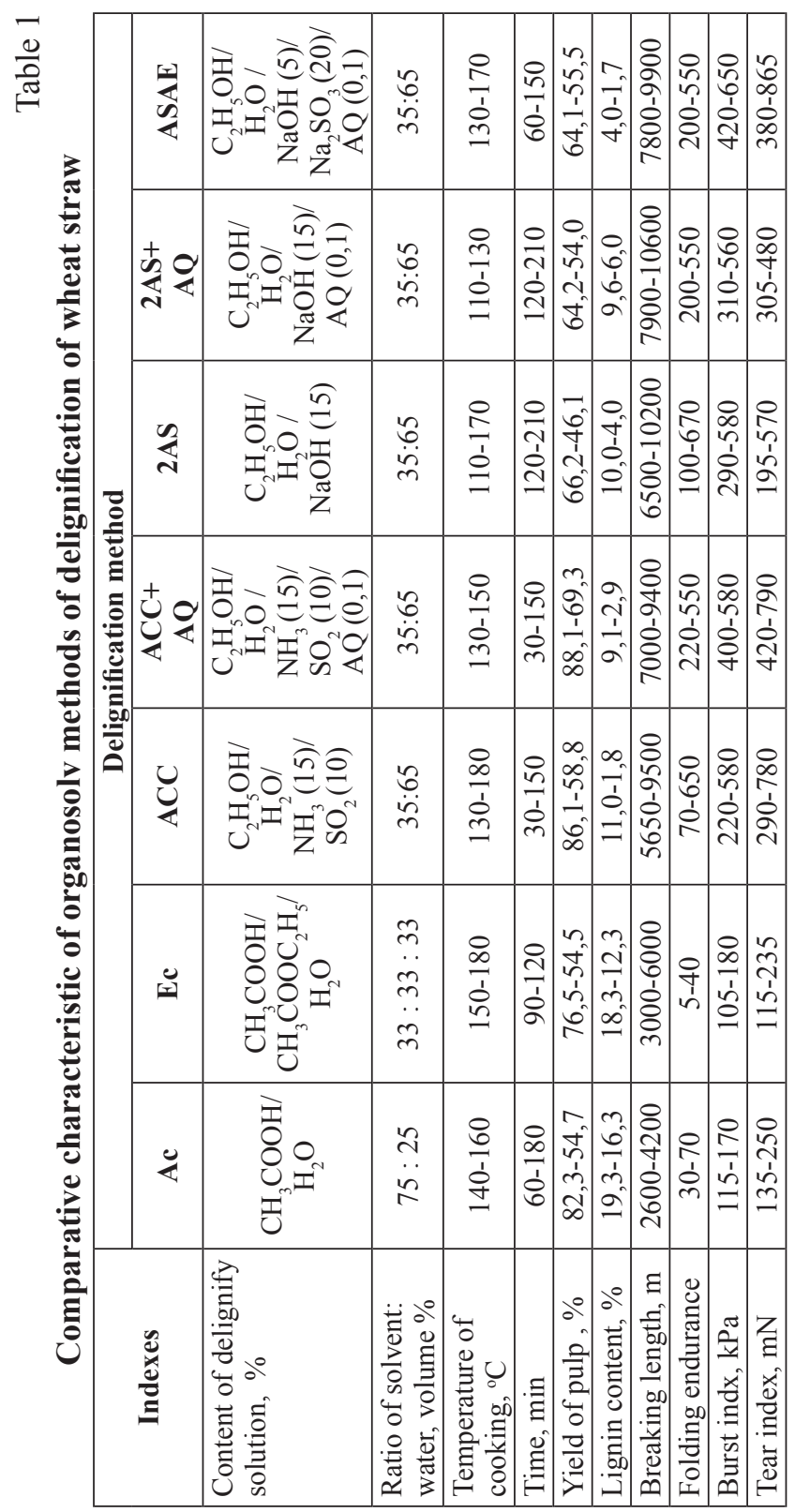


Ammonia-sulfite-alcohol, alkaline-sulphite-alcohol and two-stage alkaline-alcohol cooking of wheat straw are characterized by better straw pulp quality indices (yield, lignin content and mechanical parameters) among investigated organsolv methods of delignification, so they can be considered as alternative methods obtaining of fibrous products suitable for the production of paper and cardboard.

Bleaching of organosolv straw pulp

One of the problems of the modern PPI is the development of environmentally friendly pulp bleaching technologies, since, as it known, the use molecular chlorine for bleaching pulp is accompanied by the formation of highly toxic organochlorine compounds: chlorophenols, dioxins, furans [7, p. 30]. Therefore, the general direction of the development of pulp bleaching technologies is the development of bleaching methods without the use of molecular chlorine or completely without chloric reagents.

Bleaching of straw pulp was carried out using an environmentally friendly chemical - hydrogen peroxide with a pre-treatment stage with trilon $\mathrm{B}$ application. For comparison of the effectiveness of bleaching of ASAE and ACC straw pulp, the chlorination process with different consumption of active chlorine from 1 to $10 \%$ was carried out. The treatment of $\mathrm{t}$ pulp only with chlorine water leads to large losses of cellulose, \%: 7.2-23.5 for ASAE pulp; 6.3-11.9 for ACS pulp. After the chlorination stage, lignin in cellulose is still in a large quantity. Further alkali treatment contributes to the transfer to the solution of lignin, which precipitated on fibers of pulp, that allows one to remove $10-20 \%$ of lignin at a decrease in the yield of straw pulp by $1-2 \%$. Removal up to $50 \%$ of the lignin from organosolv straw pulp occurs at the active chlorine consumption of $3 \%$ and followed by alkaline treatment. A further increase in the consumption of active chlorine leads to a slight increase in brightnes, therefore, it is inappropriate. Thus, it can be argued that bleaching organosolv pulp with chlorine water organic is not sufficiently effective.

The process of bleaching of straw pulp with hydrogen peroxide was carried out with the consumption of chemical reagent from 1 to $10 \%$ (Table 2). More effective removal of lignin occurs during treatment of organosolv pulp with hydrogen peroxide. The removal of 50\% of lignin from pulp is achieved at a consumption of $\mathrm{H}_{2} \mathrm{O}_{2}-2 \%$. Bleaching of organosolv straw pulp with hydrogen peroxide makes it possible to increase its brightness in 
twice at $\mathrm{H}_{2} \mathrm{O}_{2}$ consumption $1-2 \%$ by weight of absolutely dry pulp, while the brightness of straw pulp after chlorination with the consumption of active chlorine of $5 \%$ of oven dry pulp increases only in 1,5 times. Further alkaline treatment reduces the brightness of organosolv straw pulp by another $2-3 \%$. It must be noted that the brightness of ASAE pulp is $7-8 \%$ higher than for ACC pulp.

To remove cations of variable valence and stabilization of the solution of hydrogen peroxide during the bleaching process, it was suggested to proceed chelating treatment of organosolv straw pulp with trilon $\mathrm{B}$, that increases the brightness of fibrous product by $8.1-10.6 \%$ (Table 3 ).

Table 2

Indicators of quality of bleaching straw pulp with hydrogen peroxide

\begin{tabular}{|c|c|c|c|c|c|c|}
\hline Consumption & \multicolumn{2}{|c|}{ Yield of pulp, \% } & \multicolumn{2}{c|}{ Lignin content, \% } & \multicolumn{2}{c|}{ Brightness, \% } \\
\cline { 2 - 7 } $\mathbf{H}_{2} \mathbf{O}_{2}, \mathbf{\%}$ & ASAE & ACC & ASAE & ACC & ASAE & ACC \\
\hline 1 & 85,6 & 74,5 & 1,39 & 1,57 & 58,8 & 73,9 \\
\hline 2 & 75,1 & 70,4 & 1,26 & 1,31 & 60,7 & 74,6 \\
\hline 3 & 71,1 & 65,5 & 1,13 & 0,99 & 62,7 & 75,7 \\
\hline 5 & 69,5 & 64,9 & 0,89 & 0,82 & 65,9 & 77,1 \\
\hline 7 & 68,8 & 61,1 & 0,84 & 0,68 & 70,6 & 78,9 \\
\hline 10 & 63,7 & 57,7 & 0,81 & 0,47 & 74,3 & 80,1 \\
\hline
\end{tabular}

Table 3

\section{Indices of quality of bleached alkaline-sulphite-alcohol straw pulp}

\begin{tabular}{|c|c|c|c|c|}
\hline \multirow{2}{*}{ Indices of pilp } & \multirow{2}{*}{$\begin{array}{c}\text { Consumption } \\
\mathrm{H}_{2} \mathrm{O}_{2} \%\end{array}$} & \multicolumn{3}{|c|}{ Scheme of bleaching } \\
\hline & & $\mathbf{P}-\mathbf{A}$ & $\mathbf{C}-\mathbf{P}$ & $\mathbf{C}-\mathbf{P}-\mathbf{A}$ \\
\hline \multirow{2}{*}{$\begin{array}{l}\text { Yield, \% from } \\
\text { unbleached pulp }\end{array}$} & 3 & 97,2 & 97,5 & 96,5 \\
\hline & 5 & 96,8 & 97,1 & 96,1 \\
\hline \multirow{2}{*}{$\begin{array}{l}\text { Content of residual } \\
\text { lignin, \% }\end{array}$} & 3 & 0,85 & 0,89 & 0,71 \\
\hline & 5 & 0,72 & 0,76 & 0,62 \\
\hline \multirow[t]{2}{*}{ Brightness, $\%$} & 3 & 68,5 & 77,6 & 79,1 \\
\hline & 5 & 72,7 & 78,1 & 80,8 \\
\hline
\end{tabular}

Bleaching of organosolv straw pulp with hydrogen peroxide makes it possible to increase its brightness in twice at $\mathrm{H}_{2} \mathrm{O}_{2}$ consumption $1-2 \%$ of oven dry pulp, while the brightness of straw pulp after chlorination with the consumption of active chlorine $5 \%$ of oven dry pulp increases only in 1,5 times. Further alkaline treatment reduces the brightness of organosolv 
straw pulp by another $2-3 \%$. It should be noted that the brightness of ASAE straw pulp is $7-8 \%$ higher than those for ACC straw pulp.

Investigation of papermaking properties of pulps showed that organosolv straw pulp obtained by alkaline-sulfite-alcohol and ammonia-sulfite alcohol methods of delignification are easy to bit, with a lower energy consumption compared to sulfate and sulfite wood pulp.

The use of unbleached ASAE and ACC straw pulp, instead of wood pulp in the composition with the recycling paper, allows one to receipt packaging cardboard, and the use of alkaline-sulphite-alcohol straw pulp in a bleached form in the writing paper can replace up to $75 \%$ sulfate softwood pulp, and, thus, substantially reduce the cost of final products.

\section{Optimization of organosolv methods for the obtaining straw pulp}

The experimental studies allows to assert that fibrous products obtained by such organosolvent methods of cooking wheat straw, as ASAE, ACC+AQ and $2 \mathrm{AS}+\mathrm{AQ}$, are characterized with the highest physical and mechanical parameters. To obtain the mathematical dependences of the quality indices of straw pulp $\left(Y_{i}\right)$ from the main technological factors $\left(x_{i}\right)$ of proposed organosolv cooking of wheat straw, a full factor design of 22 was used [8, p. 207]. The temperature of cooking $\left(x_{1}\right)$ and the cooking time $\left(x_{2}\right)$ were chosen as factors $x_{i}$ that affect the quality indices of organosolv straw pulp and were studied. For the initial indices of straw pulp $Y_{i}$, which determine the quality of organosolv straw pulp, were selected: yield of fibrous product $\left(Y_{1}\right)$, degree of delignification $\left(Y_{2}\right)$, content of residual lignin $\left(Y_{3}\right)$, breaking length $\left(Y_{4}\right)$, folding endurance $\left(Y_{5}\right)$, burst index $\left(Y_{6}\right)$ and tear index $\left(Y_{7}\right)$. The statistical mathematical model of the process of obtaining pulp for two independent variables has the following form:

$$
y_{i}=b_{0}+b_{1} \cdot x_{1}+b_{2} \cdot x_{2}+b_{3} \cdot x_{1} \cdot x_{2}+b_{4} \cdot x_{1}^{2}+b_{5} \cdot x_{2}^{2},
$$

where $y_{i}$-indicator of the quality of straw pulp;

$b_{0}, b_{1}, b_{2}, b_{3}, b_{4}, b_{5}$ - coefficients of the mathematical model;

$x_{1}$ i $x_{2}$ - value of cooking factors in coded form.

As a result of the mathematical treatment of the experimental data of organosolv pulping of wheat straw, regression equations, which adequately describe the dependence of the indicators $Y_{i}$ on the technological factors $x_{i}$, were obtained. The values of the obtained coefficients of the regression equations are given in Table 4. 
Table 4

Values of coefficients of mathematical models of cooking processes of straw pulp by organosolv methods of delignification

\begin{tabular}{|c|c|c|c|c|c|c|c|c|}
\hline \multirow{2}{*}{ Coefficients } & \multicolumn{7}{|c|}{ Organosolv pulp quality indices $\left(\boldsymbol{V}_{i}\right)$} \\
\cline { 2 - 8 } & $\boldsymbol{V}_{1}$ & $\boldsymbol{y}_{2}$ & $\boldsymbol{y}_{3}$ & $\boldsymbol{y}_{4}$ & $\boldsymbol{y}_{5}$ & $\boldsymbol{V}_{6}$ & $\boldsymbol{y}_{7}$ \\
\hline \multicolumn{7}{|c|}{ ASAE } \\
\hline$b_{0}$ & 60.606 & 16.727 & 3.104 & 9123.1 & 363.53 & 640.16 & 552.44 \\
\hline$b_{1}$ & -3.971 & -4.150 & -1.103 & -586.51 & -76.39 & -157.53 & -70.37 \\
\hline$b_{2}$ & -1.269 & -2.503 & -0.375 & 604.99 & 113.67 & 120.66 & 44.19 \\
\hline$b_{3}$ & 0.009 & -0.214 & 0.123 & 161.89 & -75.43 & 9.05 & -3.76 \\
\hline$b_{4}$ & -0.227 & -0.520 & -0.111 & -441.12 & -53.48 & -35.71 & -32.23 \\
\hline$b_{5}$ & -0.195 & 0.031 & 0.011 & 48.80 & -2.61 & -12.62 & 7.88 \\
\hline \multicolumn{7}{|c|}{ ACC+AQ } & & \\
\hline$b_{0}$ & 77.005 & 31.542 & 5.176 & 8880.7 & 401.16 & 603.30 & 515.63 \\
\hline$b_{1}$ & -3.512 & -6.038 & -1.407 & -259.23 & -56.45 & 0.88 & -8.79 \\
\hline$b_{2}$ & -5.189 & -10.210 & -1.443 & 1590.1 & 200.88 & 209.27 & 108.86 \\
\hline$b_{3}$ & -0.744 & 0.885 & 0.445 & 95.18 & -26.68 & -13.44 & 10.98 \\
\hline$b_{4}$ & -0.862 & -0.463 & -0.623 & 253.27 & 48.54 & 56.23 & 7.45 \\
\hline$b_{5}$ & 2.231 & 5.213 & 1.037 & -809.15 & -45.85 & 33.48 & -20.21 \\
\hline \multicolumn{7}{|c|}{$\mathbf{2 A S + A Q}$} \\
\hline$b_{0}$ & 59,765 & 30,596 & 7,612 & 8734,4 & 297,63 & 370,74 & 537,75 \\
\hline$b_{1}$ & $-2,012$ & $-3,525$ & $-0,712$ & 831,25 & 54,50 & 73,70 & 73,87 \\
\hline$b_{2}$ & $-3,215$ & $-4,000$ & $-0,940$ & 612,50 & 108,50 & 37,89 & 47,90 \\
\hline$b_{3}$ & 0,082 & 0,075 & 0,172 & 78,75 & 29,40 & 11,85 & $-26,62$ \\
\hline$b_{4}$ & $-0,762$ & $-1,050$ & $-0,062$ & 381,25 & 41,00 & 7,20 & $-72,12$ \\
\hline$b_{5}$ & 0,243 & $-0,712$ & 0,112 & 28,12 & 12,37 & $-9,21$ & $-9,00$ \\
\hline
\end{tabular}

Different methods of optimization for finding the optimal values for the parameters of the technological process are known [8, p. 207]. One of the most common ways of solving the problem of optimizing the parameters of technological processes for several quality indices is the union of criteria (quality indices) using the generalized Harrington's desirability function $(D)$. In this method the natural values of individual quality indices $\left(y_{i}\right)$ converted into a dimensionless scale of desirability of $d$ in the interval of desirsbility from 0 to 1 . A higher numerical value on the scale of desirability corresponds to a greater desirability - from very bad $(\mathrm{d}=0,20-0,00)$ to very good $(d=1,00-0,80)[8, p .207]$. Graphic dependences of the gen- 
eralized function of desirability $D$, as an average geometric for individual desires of $d$, on the plane of technological factors $X_{1}-X_{2}$ show good coordination between all quality indicators $\left(\boldsymbol{y}_{i}\right)$.

To determine the optimal values of the technological parameters for obtaining the corresponding organosolv straw pulp by the generalized Harrington's desirable function, the limitations for each of the quality indices $\left(y_{i}\right)$ were chosen and the results are given in Table 5.

Table 5

Limitation of the quality of pulp $\left(y_{i}\right)$

for different organosolv methods of delignification of wheat straw

\begin{tabular}{|l|c|c|c|c|c|c|}
\hline \multirow{2}{*}{$\begin{array}{c}\text { Organosolv straw pulp } \\
\text { quality indices }\end{array}$} & \multicolumn{3}{|c|}{ The best value } & \multicolumn{3}{c|}{ The worst value } \\
\cline { 2 - 7 } & ASAE & ACC+AQ & 2AS+AQ & ASAE & ACC+AQ & 2AS+AQ \\
\hline Yield of pulp $\left(\boldsymbol{y}_{i}\right), \%$ & 70 & 85 & 65 & 50 & 70 & 55 \\
\hline Kappa number $\left(\boldsymbol{y}_{2}\right)$ & 8 & 20 & 22 & 25 & 55 & 36 \\
\hline $\begin{array}{l}\text { Content of residual lignin } \\
\left(\boldsymbol{y}_{3}\right), \%\end{array}$ & 1 & 3 & 6 & 5 & 9 & 10 \\
\hline Breaking length $\left(\boldsymbol{y}_{4}\right), \mathrm{m}$ & 10000 & 10000 & 11000 & 7000 & 7000 & 8000 \\
\hline Folding endurance $\left(\boldsymbol{y}_{5}\right)$, & 600 & 700 & 550 & 200 & 200 & 200 \\
\hline Burst index $\left(\boldsymbol{y}_{6}\right), \mathrm{mN}$ & 1000 & 900 & 500 & 300 & 400 & 270 \\
\hline Tear index $\left(\boldsymbol{y}_{7}\right), \mathrm{kPa}$ & 700 & 600 & 570 & 300 & 350 & 310 \\
\hline
\end{tabular}

The calculated optimal parameters of the parameters $X_{i}$ in coded form for each organosolv method are: for ASAE $X_{1}=-0,48$ i $X_{2}=1$; for ACC $X_{1}=-1 \mathrm{i} X_{2}=1$; for $2 \mathrm{AS} X_{1}=1 \mathrm{i} X_{2}=0,55$. Optimal values $X_{i}$ in encoded form and the values of quality indicators $\left(y_{i}\right)$ for each pulp at the optimum points are presented in Table 6.

Optimal values $X_{i}$ and $y_{i}$ and the results of calculations of the value of the generalized desirability function $\mathrm{D}$ indicate that the best consistency of the quality indices of organosolv pulp $\left(\boldsymbol{y}_{i}\right)$ at the determined optimal values of the technological factors $\left(X_{i}\right)$ belong to an alkali-sulfite alcohol method of wheat straw delignification (the function of desirability $\mathrm{D}$ for this method cooking of raw materials is characterized by the greatest value).

In addition to the task of multicriteria optimization, the task of finding compromise conditions for organosolv cooking of wheat straw, which 
Table 6

Optimal technological parameters of organosolv cooking and straw pulp quality indices at the optimum point

\begin{tabular}{|c|c|c|c|}
\hline Indexes & ASAE & $\mathbf{A C C}+\mathbf{A Q}$ & $2 \mathrm{AS}+\mathrm{AQ}$ \\
\hline $\begin{array}{l}\text { Parameters }\left(X_{i}\right): \\
\text { temperature of cooking, }{ }^{\circ} \mathrm{C}\left(X_{1}\right) \\
\text { time of cooking, } \min \left(X_{2}\right)\end{array}$ & $\begin{array}{l}140 \\
150 \\
\end{array}$ & $\begin{array}{l}130 \\
150 \\
\end{array}$ & $\begin{array}{l}130 \\
190 \\
\end{array}$ \\
\hline $\begin{array}{l}\quad \text { Variable functions }\left(\boldsymbol{y}_{i}\right) \text { : } \\
\text { yield of pulp, \% }\left(\boldsymbol{y}_{1}\right) \\
\text { Kappa number }\left(\boldsymbol{y}_{2}\right) \\
\text { content of residual lignin, \% }\left(\boldsymbol{y}_{3}\right) \\
\text { breaking length, } \mathrm{m}\left(\boldsymbol{y}_{4}\right) \\
\text { folding endurance }\left(\boldsymbol{y}_{5}\right) \\
\text { burst index, } \mathrm{mN}\left(\boldsymbol{y}_{6}\right) \\
\text { tear index, } \mathrm{kPa}\left(\boldsymbol{y}_{7}\right)\end{array}$ & $\begin{array}{c}61 \\
16,2 \\
3,2 \\
9880 \\
535 \\
810 \\
632 \\
\end{array}$ & $\begin{array}{c}77 \\
31,2 \\
5,1 \\
10080 \\
685 \\
915 \\
610 \\
\end{array}$ & $\begin{array}{c}55 \\
23,6 \\
6,5 \\
10330 \\
470 \\
475 \\
580 \\
\end{array}$ \\
\hline Desirability function (D) & 0,6495 & 0,6365 & 0,6248 \\
\hline
\end{tabular}

ensure high quality of the obtained straw pulp for all quality indicators $\left(\boldsymbol{y}_{i}\right)$, was also considered. Such a task was solved by constructing a compromise area on the plane of technological factors $X_{1}-X_{2}$.

In Fig. 6 the compromise areas for the studied organosolv systems are represented by shaded segments formed by the lines of quality indicators of pulp at the numerical values indicated on them.

a)

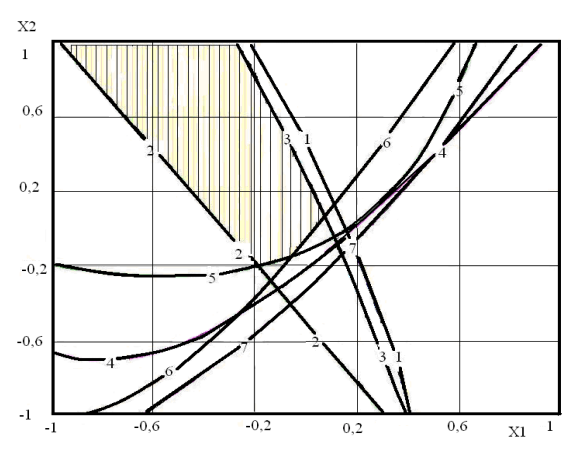

$1-y_{1}=60 \% ; 2-Y_{2}=18.0$ Kappa number; $3-Y_{3}=3 \% ; 4-Y_{4}=9000 \mathrm{~m}$; $5-y_{5}=350 ; 6-y_{6}=600 \mathrm{mN} ; 7-y_{7}=550 \mathrm{kPa}$. 
b)

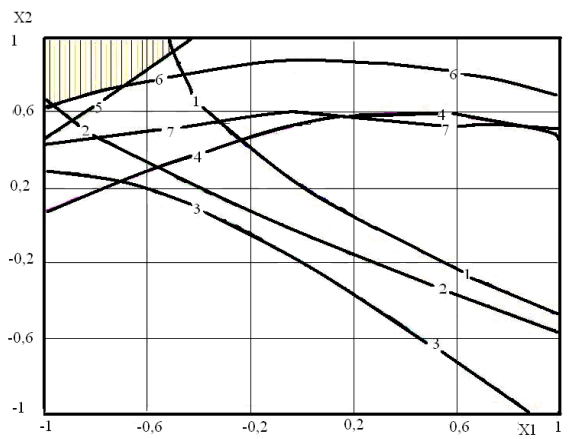

$1-Y_{1}=76 \% ; 2-Y_{2}=32.0$ Kappa number; $3-Y_{3}=5,5 \% ; 4-Y_{4}=9500 \mathrm{~m}$; $5-y_{5}=600 ; 6-Y_{6}=570 \mathrm{mN} ; 7-y_{7}=810 \mathrm{kPa}$.

c)

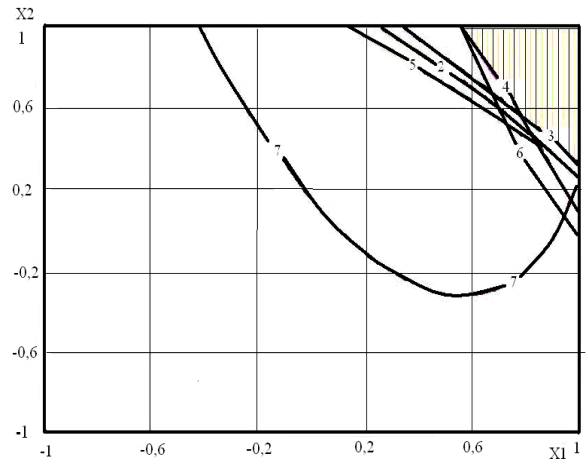

$1-y_{1}=56 \% ; 2-y_{2}=25.0$ Kappa number; $3-y_{3}=6,6 \% ; 4-y_{4}=10000 \mathrm{~m}$; $5-y_{5}=430 ; 6-Y_{6}=450 \mathrm{mN} ; 7-Y_{7}=545 \mathrm{kPa}$.

Fig. 6. Compromise areas of processes of alkaline-sulfite-alcohol (a); ammonia-sulfite-alcoholic (b); two-stage alkaline-alcoholic (c) cooking of wheat straw

Alkaline-sulfite-alcoholic cooking of straw pulp in accordance with calculated optimal values of technological parameters allows to obtain pulp, which has mechanical parameters close to those shown in Table 6 (error $+/-10 \%)$. 


\section{Selectivity and kinetic characteristics of the solvolytic delignification of wheat straw}

In order to compare the selectivity of the dissolution of lignin by investigated organosolv methods of delignification of wheat straw, calculations of such parameters as: selectivity (S1, \%), degree of removal of carbohydrates (DRC, \%) and degree of delignification (DD, \%) by the following equations were performed $[9$, p. 34]:

$$
\begin{gathered}
S l=\left(\frac{Y}{100}-\frac{L \cdot D D}{100}\right) \cdot 100 ; \\
D R C=100-Y \cdot \frac{100-L_{f}}{100-L_{i}} ; \\
D D=100-\frac{Y \cdot L_{f}}{L_{i}},
\end{gathered}
$$

where $\mathrm{L}_{\mathrm{i}}$-content of lignin in initial raw material, $\%$;

$\mathrm{Y}-$ yield of pulp, \%;

$\mathrm{L}_{\mathrm{f}}$ - content of lignin in final pulp, $\%$.

In table 7 the range of changes in the indices of selectivity of organosolv processes of wheat straw delignification for separate temperature-time intervals are given.

Table 7

\section{Indicators of selectivity of organosolv processes of delignification of wheat straw}

\begin{tabular}{|c|c|c|c|c|c|}
\hline $\begin{array}{c}\text { Method of } \\
\text { delignification }\end{array}$ & Temperature, ${ }^{\circ} \mathbf{C}$ & Time, $\mathbf{m i n}$ & $\begin{array}{c}\text { SI, } \\
\mathbf{\%}\end{array}$ & $\begin{array}{c}\text { DRC, } \\
\mathbf{\%}\end{array}$ & $\begin{array}{c}\text { DD, } \\
\mathbf{\%}\end{array}$ \\
\hline \multirow{2}{*}{ Ac } & 140 & $60 \ldots 180$ & $98 \ldots 75$ & $0,5 \ldots 30$ & $21 \ldots 49$ \\
& 160 & $60 \ldots 180$ & $94 \ldots 68$ & $5 \ldots 38$ & $34 \ldots 58$ \\
\hline \multirow{2}{*}{ Ec } & 150 & $60 \ldots 310$ & $98 \ldots 85$ & $0,6 \ldots 12$ & $11 \ldots 41$ \\
& 170 & $60 \ldots 180$ & $97 . .63$ & $6 \ldots 38$ & $28 \ldots 68$ \\
\hline \multirow{2}{*}{ ACC } & 130 & $30 \ldots 150$ & $96 \ldots 90$ & $2 \ldots 3$ & $61 \ldots 81$ \\
& 150 & $30 \ldots 120$ & $91 \ldots 82$ & $11 \ldots 15$ & $81 \ldots 90$ \\
\hline \multirow{2}{*}{ ACC+AQ } & 130 & $30 \ldots 150$ & $98 \ldots 96$ & $0,5 \ldots 1,9$ & $68 \ldots 84$ \\
& 150 & $30 \ldots 120$ & $96 \ldots 92$ & $3 \ldots 6$ & $84 \ldots 92$ \\
\hline \multirow{2}{*}{$\mathbf{2 A S}$} & 110 & $120 \ldots 210$ & $77 \ldots 71$ & $24 \ldots 29$ & $70 \ldots 77$ \\
& 130 & $120 \ldots 210$ & $74 \ldots 70$ & $27 \ldots 31$ & $74 \ldots 83$ \\
\hline \multirow{2}{*}{$\mathbf{2 A S}+\mathbf{A Q}$} & 110 & $120 \ldots 210$ & $79 \ldots 74$ & $22 \ldots 26$ & $75 \ldots 82$ \\
& 130 & $120 \ldots 210$ & $76 \ldots 68$ & $31 \ldots .35$ & $81 \ldots 86$ \\
\hline \multirow{2}{*}{ ASAE } & 130 & $60 \ldots 120$ & $97 \ldots 82$ & $17 \ldots 20$ & $89 \ldots 91$ \\
& 150 & $90 \ldots 150$ & $80 \ldots 78$ & $20 \ldots 22,5$ & $90 \ldots 93$ \\
\hline
\end{tabular}


The increase in temperature and cooking time leads to an increase in such indicators as the DRC and the DD, and the rate of selectivity decreases. Reduced selectivity connected with the predominant removal of carbohydrates in comparison with the removal of lignin and is confirmed by an increase in the DRC index in the studied temperature-time intervals. The use in 2AS, ACC and ASAE of cooking of ethanol, which play the role of a buffer, prevents the process of condensation of lignin and stabilizes the hydrocarbon part of the plant material, thereby, promoting the softly delignification process and increasing the selectivity in comparison with the selectivity of the Ac and Ec of wheat straw. Thus, the process of delignification of wheat straw by 2AS, ACC and ASAE methods is characterized by a higher selectivity of lignin removal in comparison with acetic and etheric cooking.

On the example of ACC and 2AS pulping it is shown that the application of anthraquinone improves the selectivity of the process of removal of lignin from wheat straw. In this case, the SL and the DD increase, and the DRC decreases.

Among all investigated organosolv methods of cooking of wheat straw, the highest CL and DD were reached by ammonia-sulfite-alcohol and alkaline-sulphite-alcohol methods of delignification of plant material. Therefore, they are most suitable for practical use in the pulp and paper industry.

In order to obtain deep knowledge about the essence of reactions occurring during the process of delignification of plant material and itsr optimal conditions, it is also necessary to know its kinetic characteristics. The kinetic characteristics are calculated for the following topochemical levels: Kolmogorov-Erofeev, Praut-Thompkinson, Histling-Braunstein, equations of the first and second order for which the corresponding kinetic curves of wheat straw delignification were constructed (dependence of the content of lignin on the time of cooking). The analysis of the obtained kinetic curves allows us to conclude that the organosolv delignification of wheat straw is more accurately characterized by the second-order kinetic equation, since the kinetic curves obtained by this equation have less curvature and are described by linear dependencies with correlation coefficient close to one. Calculated by analytical and by graphical methods the value of the rate constant $(\mathrm{k})$ and activation energy $(\Delta \mathrm{Ea})$ of the investigated organosolv methods of wheat straw delignification is shown in Table 8. 
Table 8

Kinetic characteristics of organosolv delignification of wheat straw

\begin{tabular}{|c|c|c|c|c|c|}
\hline \multirow{2}{*}{ 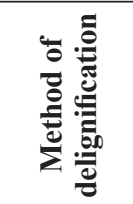 } & \multirow{2}{*}{ 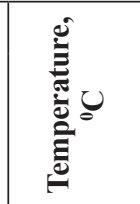 } & \multicolumn{2}{|c|}{ Analytical method } & \multicolumn{2}{|c|}{ Graphical method } \\
\hline & & $\begin{array}{c}\text { Rate constant } \\
\mathbf{k}, \mathbf{m}^{3} / \text { molecule·c }\end{array}$ & $\begin{array}{c}\text { Activation } \\
\text { energy } \mathbf{E}_{\mathrm{a}}, \\
\mathrm{kJ} / \mathrm{mol}^{2}\end{array}$ & $\begin{array}{l}\text { Rate constant } \\
\mathbf{k}, \mathbf{m}^{3} / \mathbf{m o l e c u l e} \cdot \mathbf{c}\end{array}$ & $\begin{array}{c}\text { Activation } \\
\text { energy } \mathbf{E}_{\mathrm{a}}, \\
\mathrm{kJ} / \mathbf{m o l}\end{array}$ \\
\hline Ac & $140-160$ & $7,91 \cdot 10^{-5}-1,06 \cdot 10^{-4}$ & 24,3 & $8,33 \cdot 10^{-5}-1,36 \cdot 10^{-4}$ & 35,3 \\
\hline Ec & $140-180$ & $8,11 \cdot 10^{-5}-1,87 \cdot 10^{-4}$ & 54,3 & $5,00 \cdot 10^{-5}-5,91 \cdot 10^{-4}$ & 76,2 \\
\hline $\mathrm{ACC}$ & $130-180$ & $7,61 \cdot 10^{-4}-2,27 \cdot 10^{-3}$ & 45,5 & $6,67 \cdot 10^{-4}-2,51 \cdot 10^{-3}$ & 41,5 \\
\hline $\mathrm{ACC}+\mathrm{AQ}$ & $130-150$ & $9,24 \cdot 10^{-4}-1,25 \cdot 10^{-3}$ & 25,1 & $7,12 \cdot 10^{-4}-1,33 \cdot 10^{-3}$ & 24,7 \\
\hline $2 \mathrm{AS}$ & $110-170$ & $7,00 \cdot 10^{-4}-1,19 \cdot 10^{-3}$ & 17,2 & $5,00 \cdot 10^{-4}-7,19 \cdot 10^{-4}$ & 16,6 \\
\hline $2 \mathrm{AS}+\mathrm{AQ}$ & $110-130$ & $8,24 \cdot 10^{-4}-9,98 \cdot 10^{-4}$ & 15,9 & $3,15 \cdot 10^{-4}-3,89 \cdot 10^{-4}$ & 13,4 \\
\hline ASAE & $130-170$ & $6,12 \cdot 10^{-4}-2,68 \cdot 10^{-3}$ & 52,3 & $7,22 \cdot 10^{-4}-2,83 \cdot 10^{-3}$ & 50,6 \\
\hline
\end{tabular}

The increase in the cooking temperature leads to an increase in the rate constants of organosolv delignification of wheat straw by various cooking solutions. In this case, organosolv delignification of wheat straw is characterized by lower values of activation energy in comparison with organosolv delignification of wood, for which it is in the range of $63-117 \mathrm{~kJ} / \mathrm{mol}$ [10, p. 541]. Lignin of annual plants is less polymerised, and therefore requires less energy for degradation.

The low values of the activation energy of wheat straw delignification of ASAE, ACC, ACC+AQ, $2 \mathrm{AS}$ and $2 \mathrm{AS}+\mathrm{AQ}$ methods indicate that these delignification processes are in the diffusion region. The high activation energy of the etheric cooking indicates that the delignification process takes place in the kinetic region, where the process rate is limited with the stage of a chemical reaction, which requires high energy consumption.

The application of anthraquinone during pulping leads to a decrease in the activation energy by $16.8-20.4 \mathrm{~kJ} / \mathrm{mol}$ for the ACC method of delignification, and by $1.3-3.2 \mathrm{~kJ} / \mathrm{mol}$ for the $2 \mathrm{AC}$ method.

\section{Conclusions}

Based on the experimental results obtained, technologies for the production of pulp from wheat straw by organosolv methods of delignification and conditions for their use in the composition of mass types of cardboard and paper products were developed. The higher yield and mechanical indices of 
straw pulp were obtained by delignification of the plant material with ACC, 2AS and ASAE methods. The application of anthraquinone with the consumption of $0.1 \%$ during $2 \mathrm{AC}$ and $\mathrm{ACC}$ methods of delignification of wheat straw helps to reduce the content of residual lignin and increase the mechanical characteristics of the obtained fibrous products. Straw alkali-sulfite-alcoholic pulp, according to its quality indicators, exceeds not only similar indicators for straw and reed pulp, obtained by traditional cooking methods, but also characteristics of the strength of sulfite wood pulp. Organosolv straw pulp is well bleached with the application of short bleaching schemes and non-chlorinated reagents of low costs. The scheme of bleaching such pulp using trilon $\mathrm{B}$, hydrogen peroxide and acid at low hydrogen peroxide consumption (3-5\%) allows to obtain organosolv straw pulp with a brightness of $80 \%$. The regression equations, which adequately describe the experimental data and can be used as a mathematical model of organosolv cooking of straw fibrous products with certain quality indices, were calculated. The method of multicriteria optimization of the parameters of organosolv cooking were used to defined compromise areas of the processes of delignification of wheat straw. It was shown that ammonia-sulfite-alcohol and alkaline-sulphite-alcohol methods of delignification of wheat straw are characterized with the most selectively and can be recommended for industrial application. Organosolv delignification of wheat straw is described by a second-order kinetic equation. Low values of activation energy indicate the occurrence of organosolv delignification of wheat straw in the diffusion region.

In further research, the technology for the practical use of waste solutions, which are formed during the process of organosolv delignification of plant material will be developed.

\section{References:}

1. Oral J., Sikula J., Puchy R., Hajny Z., Stehlik P., \& Bebar L. (2005). Processing of waste from pulp and paper plant. Journal of Cleaner Production, 22(13): 37-42.

2. Safdaril V., Reza V., Sigarodyl N., \& Moinuddin A. (2011). Identification of fibers of woody and non-woody plant. Species in pulp and papers. Pak. J. Bot., 43(14): 2127-2133.

3. Saberikha E., Rovshandeh J., \& Rezayati-Charani P. (2011). Organosolv pulping of wheat straw by glycerol. Cellulose Chemistry And Technology, 45(1-2): $67-75$.

4. McDonough T. J. (1993). The chemistry of organosolv delignification. Tappi Jurnal, 8(76): 186-193. 
5. Sano Y. (1989). Reactivity of $\beta-O-4$ linkages in lignin during Solvolysis Pulping. Degradation of $\beta-O-4$ lignin model compounds. Mokuzai Gakkaishi, 9(3): 813-819.

6. Barbash V., Trembus I., \& Shevchenko V. (2014). Ammonia-sulfite-ethanol pulp from wheat straw. Cellulose Chem. and Technol., 48(3-4): 345-353.

7. Fedorova E.I., Smoleva L.L. \& Zakharova A.V. (2001). Ob al'ternativakh i problemakh ECF-otbelki sul'fatnoy tsellyulozy. Tsellyuloza. Bumaga. Karton., 5-6: $30-31$.

8. Trautmann H., \& Weihs C. (2006) On the distribution of the desirability index using Harrington's desirability function. Metrika, 63(2): 207-213.

9. Simkovich B.S., Zilbergleyt M.A., Rezkov V.M. (1986). Issledovaniye protsessa delignimosti drevesiny vodnimi rastvorami uksusnoy kisloty. Khimiya drevesiny, 3: 34-38.

10. Kuznetsov B.N., Taraban'ko V.Ye., \& Kuznetsova S.A. (2008). Novyye kataliticheskiye metody $\mathrm{v}$ poluchenii tsellyulozy i drugikh khimicheskikh produktov iz rastitel'noy biomassy. Kinetiki i kataliz, 49 (4): 541-551. 